\title{
LA POSICIÓN DE LA JURISPRUDENCIA NACIONAL ACERCA DE LA PREVALENCIA DEL DERECHO PERSONAL INSCRITO SOBRE EL DERECHO REAL NO INSCRITO: ESPECIAL CONSIDERACIÓN DE LA SEGURIDAD JURÍDICA Y LA FE PÚBLICA REGISTRAL
}

\author{
Flaminio Gilberto Vigo Saldaña*
}

\begin{abstract}
Resumen
Cuando un derecho personal real se opone frente a un derecho personal inscrito con anterioridad, la jurisprudencia prefiere al primero. No obstante, se sostiene una postura contraria al indicarse que la oponibilidad de los derechos no debe darse en consideración a la naturaleza de los derechos contrapuestos sino en mérito de la publicidad que hayan adquirido, de lo contrario se enviarían mensajes que propicien, en la mayoría de los casos, fraudes y connivencia con el deudor que pretende burlar el derecho del acreedor.
\end{abstract}

Palabras clave: Derechos patrimoniales - Derecho real no inscrito - Derecho personal inscrito - Principios registrales.

\begin{abstract}
When a personal property right is enforced against a previously registered personal right, case law prefers the first one. Notwithstanding, an opposite stance is assumed indicating that the enforceability of rights should not occur based on the nature of the enforced rights but based on the publicity they had; otherwise, in most of the cases, the message would be to favor frauds and collusion with the debtor intending to evade the creditor's right.
\end{abstract}

Key words: Property rights - Unregistered real property rights - Registered personal rights - Registration principles.

\section{Sumilla}

1. El problema y su posible respuesta (a su vez, la justificación de este artículo). 2. La distinción entre los derechos reales y personales. 2.1. Los derechos reales. 2.2. Los derechos personales o de crédito. 2.3. Diferencias de los derechos reales con los derechos personales. 3. Nuestro sistema registral y sus implicancias determinantes: la seguridad jurídica. 4. La confrontación entre derechos de distinta naturaleza. 5. La posición de la jurisprudencia suprema. 6. Posición final.

\footnotetext{
* Miembro del Consejo Ejecutivo del Poder Judicial de Perú y Juez Superior Titular de la Corte Superior de Justicia de Cajamarca.
} 


\section{EL PROBLEMA Y SU POSIBLE RESPUESTA (A SU VEZ, LA JUSTIFICACIÓN DE ESTE ARTÍCULO)}

La duda genera el interés por investigar. Partimos de esta premisa para plantear la pregunta que origina esta investigación: ¿por qué el derecho personal (embargo inscrito) debe prevalecer sobre el derecho real (propiedad no inscrita), cuando se contraponen derechos de distinta naturaleza? Contrario a la posición mayoritaria, creemos que el derecho personal inscrito debe primar sobre el derecho real no inscrito para así garantizar la seguridad jurídica y la fe pública registral.

Como puede apreciarse, en la raíz de este problema se halla la discordancia en cuanto al principio de prioridad - prior tempore, prior iure. Si bien la primacía del derecho real sobre el derecho personal, en atención a la oponibilidad erga omnes del primero, está consagrada en nuestra jurisprudencia, se han evidenciado situaciones que, al aplicar esa concepción, ocasiona resultados injustos. A partir de la teoría y de la casuística jurisprudencial se ha investigado el porqué no debería primar el derecho real no inscrito. Así, se pretende brindar nuevos aportes en cuanto al fundamento del sistema registral pues como lo expresa Cornejo: “El Estado con el fin de mantener la libertad, la convivencia armónica, la seguridad, el orden público, la moralidad, la salud y el bienestar general de sus habitantes, impone por medio de la ley de conformidad con los principios constitucionales, limitaciones razonables al ejercicio de los derechos individuales"1.

\section{LA DISTINCIÓN ENTRE LOS DERECHOS REALES $Y$ PERSONALES}

Nuestro sistema jurídico civil patrimonial mantiene una categorización normativa que distingue a los derechos reales de los derechos personales. Esta clasificación persiste, a pesar de reconocerse como una distinción criticable y abandonada por gran parte de la doctrina, pues carece de sustento técnico y no constituye un instrumento útil en la práctica. Por el contrario, se ha convertido en un mito que genera imprecisiones y constituye un lugar común en los fallos jurisdiccionales.

Así, la teoría tradicional señala que los derechos reales pueden hacerse valer frente a cualquier tercero, lo que no sucede con los derechos de crédito, los cuales solo pueden oponerse entre partes involucradas en la respectiva relación obligatoria. Por lo tanto, si se presenta un conflicto entre ambos tipos de derechos, la prevalencia del derecho real no puede ser puesta en duda. El 
fundamento de este planteamiento es la antiquísima clasificación de los derechos subjetivos que los distingue entre absolutos y relativos. De este modo, se sostiene que son absolutos los derechos que se pueden hacer valer frente a cualquier persona y que son relativos aquellos otros que, por el contrario, solo pueden oponerse frente a ciertos sujetos.

La teoría nacional que se ha ocupado directamente del artículo $2022^{\circ}$ del Código Civil, ha obviado un detalle: reconoce que los derechos de crédito también poseen oponibilidad, que dista mucho de ser inter partes.

Así, debe advertirse que la distinción entre unos derechos que pueden ser opuestos a todos los individuos y otros que pueden ser opuestos a algunos, resulta caduca. En efecto, si se considera que todos los derechos subjetivos no constituyen nada más que medios de realización o satisfacción de intereses, no parece factible admitir que la relevancia de algunos esté limitada por el ámbito de la concreta relación jurídica en la que se desenvuelve, tal como lo postula la mayoría de nuestros jueces. Debido a que tales intereses se ubican en un plano de convivencia, es absolutamente posible que cualquier tercero provoque su lesión, de donde se deduce, necesariamente, que todos los derechos subjetivos pueden ser opuestos a cuanto individuo esté en aptitud potencial de lesionarlos.

Si bien resulta adecuado que, en aras de la seguridad jurídica y del fluido intercambio de bienes, se debe utilizar el principio de prioridad registral, que debe ser aplicado para todo tipo de derecho, ello tiene que hacerse sobre la base de un análisis ponderado de la segunda parte del artículo $2002^{\circ}$ del Código Civil.

\subsection{Los derechos reales}

La importancia que tienen los derechos reales en la economía, la política y la sociedad en general, determinó que desde antiguo se limitasen y estuvieran condicionados a su creación legislativa, de modo que no pudiesen existir otros que no se hallaren regulados por la ley (Arias-Schreiber ${ }^{2}$ ). Existe en esta área, por lo tanto, una excepción a la clásica amplitud de los actos jurídicos. Se ha considerado válidamente que, si se permitiese que por voluntad de las partes se creasen toda suerte de derechos reales, la consecuencia sería particularmente negativa para la seguridad y tranquilidad económico-social; sin embargo, no obstante ello resulta difícil ofrecer un concepto de lo que debe entenderse por derecho real. Se podría señalar que por derecho real entendemos el derecho de bienes o de cosas. Por tanto, en una primera aproximación podemos decir que el derecho real supone una relación entre persona y cosa. 
Planiol y Ripert ${ }^{3}$ señalan que para la concepción clásica existe derecho real cuando una cosa se encuentra sometida completa o parcialmente al poder de una persona en virtud de una relación inmediata que puede ser invocada contra cualquier otra. Esta definición implica, como carácter esencial del derecho real, la creación de una relación entre una persona y una cosa.

Con esto quiere expresarse que en todo derecho real no existe intermediario entre la persona que sea su titular y la cosa a la cual se refiera el derecho. El derecho real no supone más que dos elementos: una persona, sujeto activo del derecho y una cosa determinada, objeto de dicho derecho.

La doctrina nacional, por intermedio de Torres Vásquez, precisa que "El derecho real es el que nos pertenece directamente sobre un bien en orden a la satisfacción de un interés económico y es oponible frente a todos. Responde al instinto natural del sujeto de tener el poder de utilizar un bien, sin intermediarios y sin ser estorbado por nadie, con el fin de satisfacer intereses económicos. Se ejerce dentro de los límites de la ley, siendo que esta reconoce a la propiedad como el poder más amplio, puesto que le otorga las facultades de usar, disfrutar, disponer y reivindicar un bien y al derecho de habitación como el más limitado, debido a que se concreta a la sola facultad de morar en una casa" ${ }^{\prime 4}$.

Arias-Schreiber, indica que "los derechos reales no vienen a ser sino derechos subjetivos que, incidiendo sobre los objetos exteriores a la persona, autorizan al sujeto de un determinado señorío" ${ }^{\prime 2}$.

En definitiva, para conceptuar al derecho real es preciso considerar los dos aspectos bajo los que se presenta. En su aspecto externo se expresa la obligación general, que tiene por objeto hacer que se respete la situación del titular con relación a la cosa, obligación pasiva que puede sin embargo revestir a veces forma positiva, constriñendo a los terceros a realizar una prestación. En su aspecto interno, el derecho real representa un poder sobre la cosa. Este poder no lo constituye solamente la posesión.

La misma posesión no es tampoco una simple situación de hecho sino un verdadero derecho puesto que ella está protegida por acciones judiciales. El poder del propietario está determinado y limitado por la ley, que es la que concede a la relación jurídica, resultante del derecho real, un carácter diferente. En ese sentido, podemos definir el derecho real como el derecho que impone a toda persona la obligación de respetar el poder jurídico que la ley confiere a una persona determinada para reiterar de los bienes exteriores 
todo o parte de las ventajas que confiere la posesión de ellos, o si se prefiere el derecho que, dando a una persona el poder jurídico directo e inmediato sobre una cosa, es susceptible de ser ejercitado, no solamente contra una persona determinada, sino contra el mundo.

Para completar el concepto de derecho real se suele hacer referencia a la distinción entre este y el derecho de crédito u obligación. Derechos reales son aquellos que atribuyen a su titular un derecho pleno sobre una cosa, un bien. Derecho de obligación es aquel que atribuye a su titular la facultad de exigir una prestación (de dar, hacer o no hacer) a un tercero.

\subsection{Los derechos personales o de crédito}

Los derechos personales o de crédito constituyen derechos de contenido patrimonial entre dos personas, cuyo objeto son las prestaciones ajenas en cuanto puedan proporcionar una cierta utilidad al acreedor. Ferrero Costa, citando a León Barandiarán $(2001,75)$, señala que "son derechos de naturaleza transitoria, pues la facultad correspondiente a ella se agota al hacerse efectiva, mientras que las facultades correspondientes a un deber jurídico distinto al obligacional no se agota por su uso normal".

Resulta relevante traer a colación lo expresado por Jorge Eugenio Castañeda cuando afirma: “[...] el derecho real tiene entre sus atributos la persecución (rei persecutoria) mientras el de las obligaciones no. De otro lado el derecho obligacional puede consistir en un dar, hacer o no hacer, mientras que el derecho real da nacimiento a una obligación de no hacer (de los demás) de carácter universal" 6 .

En definitiva podemos señalar que el derecho personal es aquel en que una persona es individualmente sujeto pasivo del derecho o en términos más sencillos, un derecho personal es aquel que otorga la facultad de obligar individualmente a una persona a una prestación cualquiera: a dar, suministrar, a hacer, a no hacer alguna cosa.

Sin embargo, dentro de las varias críticas existentes, es importante precisar que Planiol y Ripert ${ }^{7}$ señalan que al derecho de crédito comúnmente se le llama derecho personal y su uso ha sido muy difundido en la medida que las palabras "derecho personal" forman una antítesis perfecta de los términos "derecho real". Sin embargo, este uso es molesto y debería ser abandonado porque la expresión "derecho personal" es anfibológica, pues aparte del sentido ya mencionado, se puede entender en otros sentidos como, por 
ejemplo, que dichos derechos no pasan a sus herederos y que hay derechos excepcionales que no pueden ser ejercidos por otros ni siquiera en vida de su titular, por lo que cuando se dice derecho personal se corre el riesgo de no ser comprendido.

\subsection{Diferencias de los derechos reales con los derechos personales}

Sostiene Díez-Picazo que "[...] la distinción de los derechos patrimoniales en derechos reales y derechos de crédito tiene una extraordinaria importancia teórica, porque, en la doctrina del derecho civil patrimonial constituye una especie de columna vertebral de todo el sistema, que aparece montado como una yuxtaposición de un derecho de obligaciones, que sería el campo de los derechos personales o de crédito, y un derecho de cosas que es el campo de los derechos reales. Además, que tiene una importancia práctica en la medida que es utilizada por los textos legales y, en especial en el Código Civil" ${ }^{8}$. El derecho romano estableció una importante diferencia entre dos tipos de acciones que eran las llamadas acciones in rem y las acciones in personam. Mediante la primera el demandante trata de obtener lo que es suyo y la segunda se ejercita cuando se demanda a alguien que nos debe algo en virtud de un contrato o de un delito. En la misma línea de ideas, entre nosotros Torres Vásquez ${ }^{9}$ (2006, 53) señala que los romanos no clasificaron los derechos, sino las acciones in re $\mathrm{y}$ acciones in personam.

Siguiendo la tesis clásica, los derechos patrimoniales pueden tener por objeto las llamadas realidades del mundo exterior (derechos reales); o pueden tener por objeto los llamados actos del hombre (derechos obligacionales). El primero, es un derecho que recae directamente sobre el bien, sin necesidad de una persona obligada. El segundo, es un derecho a exigir de una persona determinada cierta prestación que puede consistir en dar, hacer o no hacer. Un ejemplo de esta última categoría: si $X$ ha prestado a $Y$ una determinada suma de dinero, $Y$ se encuentra obligado a la restitución del dinero. El derecho de $X$ no recae en forma directa sobre algún objeto concreto, pues solamente tiene el derecho a exigirle a $Y$ la restitución del valor ${ }^{10}$. En buena cuenta, X no es "propietario" de la suma de dinero, solo tiene el derecho como acreedor de exigírselo al deudor $Y$, necesitando aquél cooperación de este (a través del pago) para ver satisfecho su interés. Muy distinto es el caso de un propietario que no necesita de ningún deudor (o persona obligada para ver cumplido su interés). Es el titular del bien y por esa circunstancia nadie puede interferir en su goce ${ }^{11}$. 
Flaminio Gilberto Vigo Saldaña - Prevalencia del derecho personal inscrito sobre el derecho real no inscrito

\section{NUESTRO SISTEMA REGISTRAL Y SUS IMPLICANCIAS DETERMINANTES: LA SEGURIDAD JURÍDICA}

Es crucial para el abordaje de este tema, tratar la configuración del sistema registral. Este sirve para otorgar seguridad jurídica en las distintas relaciones de carácter intersubjetivo entre los sujetos de derecho (personas naturales o jurídicas). Un sistema registral sustentado en los principios de prioridad de inscripción, rogación, legalidad, especialidad y publicidad, principalmente, servirá para que el Estado proteja las múltiples relaciones jurídicas de carácter patrimonial y extrapatrimonial que celebran sus ciudadanos.

Dentro del tema que nos compete desarrollar, damos especial tratamiento a los principios de oponibilidad y prioridad de rango. Por el primero podemos advertir que para oponer un derecho es preciso que este haya sido inscrito con anterioridad al de aquel a quien se opone. Esto tiene correlato con el segundo principio a tratar, que es el de prioridad de rango. Así, la prioridad en el tiempo va a determinar la preferencia de los derechos que otorga el registro.

El registro va a otorgar seguridad jurídica de manera que si existiera un derecho que se quiera oponer frente a uno previamente inscrito, de plano se preferirá al derecho inscrito. Sin embargo, encontramos una situación en el segundo párrafo del artículo $2022^{\circ}$ del Código Civil, en la que aparentemente no se va a tomar en cuenta el momento de la inscripción para determinar la preferencia de un derecho; esto sucederá cuando se confronten derechos de distinta naturaleza; es decir, derechos reales y personales.

Cuando se genere este supuesto, en el cual un derecho real se oponga frente a un derecho personal inscrito con anterioridad, gran parte de la jurisprudencia prefiere independientemente del registro, al derecho real, resquebrajándose así la razón de ser del registro, la cual es otorgar seguridad jurídica erga omnes.

El principio de prioridad preferente establece que la prioridad en el tiempo de la inscripción determina la preferencia de los derechos que otorga el registro, otorgando así seguridad a quien inscribe su derecho con fecha anterior. Sin embargo, el segundo párrafo del artículo $2022^{\circ}$ del Código Civil, prescribe que, tratándose de derechos de diferente naturaleza se aplicarán las disposiciones del derecho común. Viene entendiéndose que en este caso, tendrán preferencia los derechos reales frente a los derechos personales, inaplicándose así la razón y fines de los registros públicos sujetos a los principios de legalidad y efectividad de los actos jurídicos que se realizan sobre la base de la situación que fluye de las inscripciones registrales que existan. 
En cuanto al principio de especialidad, está contemplado en el artículo IV del Título Preliminar del Reglamento General de los Registros Públicos y alude a que cada inmueble tiene como correlato una sola, única, exclusiva y excluyente partida registral donde está inmatriculado el bien. Por ejemplo, una sola persona puede tener varios inmuebles de los cuales es propietario, pero cada inmueble en particular tiene o está inscrito en una partida registral diferente de los demás inmuebles.

Esto no solo sucede con bienes inmuebles, sino con cualquier bien, acto o contrato inscribibles. Los derechos inscribibles, cualquiera fuere su naturaleza, al momento de su inscripción se individualizan y se vuelven únicos y exclusivos respecto de los demás derechos, así sean de igual o diferente naturaleza o pertenezcan a una misma persona; es decir, que figuren inscritos en el registro con plena determinación de su extensión y alcance en la partida, folio, asiento al que pertenecen o al que corresponden.

En el principio de publicidad, contenido en el artículo $2012^{\circ}$ del Código Civil y los artículos I y II del Título Preliminar del Reglamento General de los Registros Públicos, se establece una presunción iure et de iure, según la cual toda persona tiene conocimiento de las inscripciones, o mejor aún, del contenido del registro. Este principio está referido a los mecanismos previstos en el reglamento registral en materia de publicidad, a fin de dar a conocer el contenido de los asientos registrales, sea a través de la manifestación directa de los libros y las fichas registrales, o mediante los certificados y copias expedidas por el Registro a quien lo solicite, sin importar el fin que tengan dichos documentos.

Este principio es muy importante pues opera frente a terceros cuando un derecho o acto se inscribe y es oponible a otros que lo manifiestan suyo, de tal manera que la publicidad de este derecho o acto es de conocimiento de terceros ya que, como se explicó, la veracidad de la publicidad registral se presume sin admitir prueba en contrario. Existen dos clases de publicidad, la material (por la cual, el contenido de las partidas registrales produce efectos con respecto a los terceros, aún cuando estos no tengan conocimiento de su contenido: artículo $1^{\circ}$ del Texto Único Ordenado del Reglamento General de los Registros Públicos) y la publicidad formal (otorgada por el Registro a través de sus funcionarios: artículo II del mismo cuerpo legal). 


\section{LA CONFRONTACIÓN ENTRE DERECHOS DE DISTINTA NATURALEZA}

A nivel de doctrina nacional debemos empezar citando lo expresado en la Exposición de Motivos del Código Civil, pues señala que "[...] si se tratara de un enfrentamiento entre un derecho personal y uno real, y a esto alude la segunda parte del artículo, tendrá preferencia el titular del derecho real porque goza de la oponibilidad erga omnes, que no tiene el derecho personal y además porque el real goza de lo que se llama energía persecutoria, de la que también carece el derecho personal".

A favor de la primacía del derecho personal, comentandola resolución casatoria recaída en el Expediente $N^{\circ}$ 527-2003, Avendaño Arana ha expresado que “[...] para la oponibilidad de derechos sobre un mismo bien no debe importar la supuesta naturaleza real o personal del derecho involucrado. Lo relevante es la publicidad". Prosigue diciendo "No hay razón para que prevalezca la propiedad sobre un embargo, si este último se inscribió primero. Si una persona vende su propiedad y el comprador no registra su adquisición, el adquirente tiene un derecho que no puede oponer a todos"12.

El problema no da visos de una solución armónica. De un lado está el derecho real, que no obstante tener como una de sus características el principio de oponibilidad erga omnes basado desde siempre en la apariencia de derecho que genera el detentar la posesión - como condición básica de los derechos reales de goce - y por otro lado, el derecho personal, el cual genera vínculos jurídicos invisibles a los ojos del colectivo social. Asumir la prevalencia del derecho real respecto del derecho personal tiene su razón de ser - obviamente- en el elemento "apariencia de derecho", y es por ello que ante una disyuntiva como la que se observa, de ver enfrentados un derecho real y personal, se deba optar por el primero. Sin embargo, ocurre que el registro, en una realidad como la nuestra puede cumplir un mejor papel si de oponibilidad frente a terceros hablamos.

En un medio dominado por la globalización, en el que las relaciones sociales de los hombres ya no se guían necesariamente por la vecindad, habida cuenta que en muchos de los casos, moradores de un mismo inmueble no tienen trato alguno y convendría señalar, por decirlo de alguna manera, que estamos ante una "sociedad de anónimos", el registro resulta ser una herramienta mejor adaptada a la negociación de bienes o valores, de suerte que la verificación en su fuente de datos, podrá conjurar maniobras fraudulentas y mal intencionadas orientadas a aprovechar la confianza y buena fe de los contratantes. 
El registro nacional, si bien imperfecto, resulta ofrecer mayores garantías al trato mercantil y civil. Bajo el auspicio de los principios que lo cobijan, como son la publicidad, especialidad, legalidad, tracto sucesivo, legitimación, fe pública registral, prioridad preferente y prioridad excluyente, regulados en los artículos $2011^{\circ}, 2012^{\circ}, 2013^{\circ}, 2014^{\circ}, 2015^{\circ}, 2016^{\circ}$ del Código Civil, desarrollados en el Título Preliminar del Texto Único Ordenado del Reglamento General de los Registros Públicos, el registro puede ser un mejor aliado de la seguridad jurídica y buena fe de terceros, al tiempo de determinar el valor de derechos de distinta naturaleza, como eventualmente lo pueden ser el derecho personal y el real.

La realidad no hace más que darnos la razón, pues la propiedad como derecho real pleno, en la mayor parte de nuestro país es acreditada con títulos imperfectos, que ni siquiera resultan ser documentos públicos en muchos casos. En un contexto como este, sostener que un derecho real es superior a uno personal que se encuentra respaldado por la fe registral, simplemente es cerrar los ojos frente a una grave injusticia en ciernes. Somos uno de los convencidos de que la calidad de los títulos y derechos inscritos en el registro, sean estos personales o reales, son de mayor calidad a los que no se encuentran inscritos en él, pues basta leer el Reglamento General de Registros Públicos para darnos cuenta que al tiempo de proceder a la inscripción de los títulos, existe un escrutinio de mayor rigor que el que eventualmente hagan funcionarios como los notarios públicos, jueces de paz, entre otros, al extender documentos de transferencia de derechos.

Así, por ejemplo, en el artículo $32^{\circ}$ de la norma citada se establece que los alcances de la calificación comprende: a) la confrontación de títulos a inscribirse con los asientos de inscripción de la partida registral en la que se habrá de practicar la inscripción, así como con los antecedentes registrales, b) verificación de obstáculos que emanen de la partida en la que deberá practicarse la inscripción, c) verificación de la validez y la naturaleza inscribible del acto o contrato, así como la formalidad del título en el que este consta y la de los demás documentos presentados, d) comprobación que el acto o derecho inscribible se ajuste a la corrección normativa, e) verificación sobre la competencia del funcionario administrativo o notario que autorice o certifique el título; f) verificación de la capacidad de los otorgantes por lo que resulte del título, de la partida registral y de los antecedentes registrales, g) verificación de la capacidad de representación invocada por los otorgantes; h) búsqueda de los datos en los índices y partidas registrales respectivos. 


\section{LA POSICIÓN DE LA JURISPRUDENCIA SUPREMA}

Justamente por la multiplicidad de vinculaciones contractuales o acciones que generan a su vez derechos personales y derechos reales, estudiamos veintitrés ejecutorias supremas sobre el tema, referidas a la posición de la jurisprudencia. Comentaremos estas ejecutorias, antes de emitir nuestra apreciación personal. Dichas ejecutorias corresponden al universo de resoluciones emitidas sobre el tema investigado entre 1996 y 2006, revisándose los pronunciamientos de las Salas Civil Permanente y Civil Transitoria de la Corte Suprema de Justicia de la República en procesos de conocimiento en los que se emitió pronunciamiento sobre el fondo.

De esas veintitrés ejecutorias, las dieciocho primeras ${ }^{13}$ se muestran a favor de la preeminencia del derecho real no inscrito frente al derecho personal inscrito, siendo que las cinco últimas ${ }^{14}$ adoptan el criterio de otorgarle preeminencia al derecho personal inscrito sobre el derecho real no inscrito.

Del análisis de esas resoluciones precedentes, se infiere que los principales criterios asumidos por nuestra judicatura, que sustentan la posición de prevalencia de los derechos reales sobre los derechos personales, se pueden resumir en:

a) Cuando concurren dos derechos de distinta naturaleza se aplica la segunda parte del artículo $2022^{\circ}$ del Código Civil; es decir, el derecho común, de conformidad con lo expresado en la Exposición de Motivos del Código Civil.

b) El artículo $949^{\circ}$ del citado Código es una norma de derecho común.

c) Quien aparece en el registro público inscrito como propietario, no lo es necesariamente.

d) La preferencia dentro los derechos se determina solo por la certeza y la fecha en que se constituyeron, sin referencia a la fecha de la inscripción registral.

e) Las disposiciones del derecho común tienen preferencia sobre la disposición general del artículo $2016^{\circ}$ del Código Civil.

f) La inscripción en los registros públicos no es constitutiva de derechos, por lo que no se exige dicha inscripción para que la transferencia quede perfeccionada.

g) El derecho real es un derecho erga omnes.

h) El principio de prioridad registral solo se aplica para los casos de conflictos entre derechos de la misma naturaleza, mas no para el caso de conflictos entre derechos de distinta índole, en el que se aplican las disposiciones del derecho común. 
i) El segundo párrafo del artículo $2022^{\circ}$ del Código Civil, constituye una excepción al principio de prioridad previsto en el artículo $2016^{\circ}$ del mismo cuerpo legal.

j) Al contraponer derechos de distinta naturaleza el derecho registral desaparece.

k) Las disposiciones del derecho común establecen, según lo dispone el artículo $949^{\circ}$ del Código Civil, que la sola obligación de enajenar un inmueble determinado hace al acreedor propietario de él, salvo disposición legal diferente o pacto en contrario.

1) El supuesto del artículo $2014^{\circ}$ del Código Civil, prevé la adquisición de derechos adquiridos, a su vez, por terceros de buena fe y a título oneroso, lo que es distinto al embargo en forma de inscripción, puesto que en la medida cautelar no concurre voluntad de los co-demandados y el conocimiento respecto de la libre disposición que estos hayan tenido sobre dicho bien, sin que se afecte derechos de terceros, como es el caso de los demandados.

m) La inscripción de un derecho personal en los registros públicos no lo convierte en real.

n) El artículo $1135^{\circ}$ del Código Civil no es aplicable por cuanto el titular del derecho real en momento alguno ha celebrado acto jurídico con el titular de la medida cautelar obligándose a entregar el inmueble.

o) La clasificación en derechos reales y derechos personales es el sustento de muchas decisiones jurisdiccionales, dándole prioridad al primero por razones "doctrinarias".

p) El sustento básico es que de acuerdo con el derecho común los derechos reales se pueden hacer valer frente a cualquier persona y los derechos de crédito solo pueden oponerse a terceros.

Por su parte, los principales argumentos para otorgar primacía al derecho personal inscrito sobre el derecho real no inscrito en las resoluciones estudiadas, son los siguientes:

a) Que no se debe hacer distinción entre derecho real y derecho personal.

b) Que el artículo $2016^{\circ}$ del Código Civil, referido a la prioridad de rango, no hace distinción entre derecho real y derecho personal.

c) El artículo $1135^{\circ}$ del Código acotado, constituye una norma de derecho común que recoge el principio de prioridad en el tiempo para determinar la preferencia en el derecho y resulta aplicable para la solución del conflicto.

d) Para que el derecho inmobiliario tenga la certeza necesaria para su protección y posibilidad de tráfico comercial, se requiere de su inscripción. 


\section{POSICIÓN FINAL}

Tanto en la doctrina como en la jurisprudencia se admite como regla a seguir que, cuando se enfrentan dos titulares de derechos reales, quien tendrá preferencia será aquel que inscribió primero su derecho en virtud del principio de prioridad. En cambio, cuando se enfrentan derechos de distinta naturaleza ${ }^{15}$, es decir, un derecho real y un derecho personal, se deberá aplicar el segundo párrafo del artículo $2022^{\circ}$ del Código Civil. Dentro de las normas del derecho común no existe norma específica aplicable para solucionar el conflicto surgido entre derechos.

El artículo $2022^{\circ}$ del Código Civil no debería hacer distinción entre derechos cuando estos se encuentren en colisión; mejor dicho, cuando un derecho personal se encuentre frente a un derecho real, sino que el principio de prioridad y oponibilidad debe regir también en este caso.

Existe una evidente contrariedad en la legislación, pues por un lado se trata de proteger a quien tiene la diligencia de inscribir su derecho a fin de oponerlo frente a terceros y, por lo tanto, generarle seguridad jurídica, y por otro lado, se hace una distinción innecesaria cuando se trata de derechos de distinta naturaleza, dejando entrever que los derechos personales no merecen igual protección. Los jueces, al dictar decisiones protegiendo al derecho real no inscrito, envían mensajes que propician, en la mayoría de los casos, fraudes y connivencia con el deudor que pretende burlar el derecho del acreedor.

El sistema de transferencia de propiedad adoptado por nuestro ordenamiento jurídico (consensualista), posibilita las transferencias clandestinas. Esta situación puede ser salvada si ante la eventual oposición entre un derecho real no inscrito y un derecho personal inscrito en registros públicos, se prefiere a este último.

La oponibilidad de los derechos no debe darse en consideración a la naturaleza de los derechos contrapuestos sino en mérito de la publicidad que hayan adquirido. Los principios de publicidad, oponibilidad, prioridad de rango, fe pública registral y prioridad excluyente, son criterios más afines a la justicia y a la seguridad jurídica que la vaga remisión a reglas del derecho común para resolver un problema de conflicto entre derechos de diferente naturaleza, como lo son el derecho personal y el derecho real.

No existe norma expresa que resuelva el conflicto entre un embargante que ha inscrito su derecho y un propietario que no lo ha inscrito o ha inscrito 


\section{después. Lo cierto es que los artículos $1135^{\circ}$ y $1670^{\circ}$ del Código Civil, permiten deducir que también es un principio del derecho común resolver el conflicto con terceros interesados asignando, en primera instancia, el derecho a quien primero accedió a la publicidad registral.}

1 Cornejo, Américo Atilio. Derecho registral. Buenos Aires: ASTREA, 1994, p. 201.

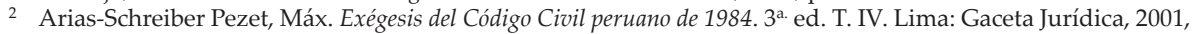
p. 44.

3 Planiol, Marcel y Ripert, Georges. Tratado práctico de derecho civil francés. Traducción española del Dr. Mario Díaz Cruz (Colegio de Abogados de la Habana). La Habana, 1938, p. 121.

4 Torres Vásquez, Aníbal. Derechos reales. T. I. Lima: IDEMSA, 2006, p. 52.

5 Arias-Schreiber Pezet, Máx. Ob. Cit., pp. $19-20$.

6 Castañeda, Jorge Eugenio. Instituciones del derecho civil. Los derechos reales. $3^{\mathrm{a}}$ ed. T.I. Lima: Fondo Editorial de la Facultad de Derecho de la UNMSM, 1965, p. 06.

7 Planiol, Marcel y Ripert, Georges. Ob. Cit., p. 357.

8 Díez-Picazo, Luis. Fundamentos del derecho civil patrimonial. Vol. II. Madrid: Editorial Civitas, 1996, pp. 58-59.

9 Torres Vásquez, Aníbal. Ob. Cit., p. 53.

10 Artículo $1219^{\circ}$ del Código Civil que prescribe: “Es efecto de las obligaciones autorizar al acreedor para lo siguiente: 1) Emplear las medidas legales a fin de que el deudor le procure aquello a que está obligado".

11 Artículo $923^{\circ}$ del Código Civil que dispone: "La propiedad es el poder jurídico que permite, usar, disfrutar, disponer y reivindicar un bien".

12 Avendaño Arana, Francisco. «Tercería: El derecho de propiedad vs. el embargo». Revista Peruana de Jurisprudencia. $\mathrm{N}^{\circ}$ 48. Año 7. Lima, Febrero, 2005, p. 62.

${ }^{13}$ Casaciones expedidas por la Corte Suprema de Justicia del Perú, recaídas en los Expedientes N ${ }^{\circ}$ 627-1996, 1892-1996, 1649-1997, 1016-1998-Cañete, 124-1999, 2236-1999, 2503-1999, 2061-2000-Lambayeque, 62-2001, 3743-2001-Lima, 1394-2002-Lima, 3030-2002-Lima, 3194-2002-La Libertad, 3800-2002-Arequipa, 2674-2003Arequipa, 100-2004-La Libertad, 638-2006-Lima, y 2103-2006-Lima.

14 Casaciones expedidas por la Corte Suprema de Justicia del Perú, recaídas en los Expedientes N ${ }^{\circ}$ 2807-99Callao, 403-2001-Piura, 2683-2001, 527-2003-Lima y 333-2003-Lambayeque.

${ }^{15}$ Los derechos reales como los derechos personales se hallan dentro de los derechos patrimoniales pues comprenden la idea de bienes, son valorables en dinero y son por esencia trasmisibles, la ley interviene en forma mínima para regularlos. En nuestro medio, para determinar la preeminencia entre los derechos reales y derechos personales se aplica el artículo $2022^{\circ}$ del Código Civil. 